\title{
A educação superior brasileira em novas configurações
}

\author{
Ramos, Luiza Olivia Lacerda'
}

Ferreira, Rosilda Arruda2

\section{Resumo}

O presente trabalho tem como objetivo analisar as novas configurações da educação superior brasileira, sobretudo a partir da implantação da Lei de Diretrizes e Bases da Educação Nacional LDB № 9.394, de 20 de dezembro de 1996. Para tanto, aborda-se em primeiro lugar e, abreviadamente, os contributos e as influências dos primeiros modelos de educação superior, a partir da revisão de literatura relativa à questão. Em seguida, apresentam-se as características do sistema de ensino superior brasileiro pós LDB desde a sua classificação, organização e estrutura, destacando os avanços e recuos decorrentes. Num terceiro tópico, são abordadas as novas configurações da educação superior sob o ponto de vista da base legal que regulamenta suas práticas. Neste contexto, faz-se um recorte especial para o Programa de Apoio a Planos de Reestruturação e Expansão das Universidades Federais (REUNI), instituído pelo Decreto $n^{\circ}$ 6.096, de 24 de abril de 2007, que se constitui na manifestação mais claras do reordenamento desse nível de ensino, analisando-se um dos seus efeitos representativos: a implantação de um novo modelo de cursos de graduação em universidades federais, denominados bacharelados interdisciplinares.

\section{Educação Superior Brasileira. Sistema de Ensino Superior Brasileiro. Bacharelado Interdisciplinar.}

\section{Resumen}

Este estudio tiene como objetivo analizar las nuevas configuraciones de la educación superior brasileña, sobre todo desde la implementación de la Ley de Directrices y Bases de la Educación Nacional LDB N`9.394, de 20 de diciembre de 1996. Por lo tanto, se aborda en primero lugar $\mathrm{y}$, en resumen, las contribuciones y las influencias de los primeros modelos de la educación superior, a partir de la revisión de la literatura sobre el tema. En seguida, presentamos las características del sistema de enseñanza superior brasileño post LDB desde su clasificación, organización y estructura, destacando los avances y retrocesos resultantes. En un tercer tema, son abordados las nuevas configuraciones de la educación superior desde el punto de vista de la base legal que regula sus prácticas. En este contexto, se haz un recorte especial para el Programa de Programa de Apoio a Planos de Reestruturação e Expansão das Universidades Federais (REUNI) establecido por el Decreto $N^{\circ} 6096$ de 24 de abril de 2007, que se

\footnotetext{
1 Doutora em Educação, professora adjunta da Universidade Federal do Recôncavo da Bahia UFRB luizaramos.ufrb@gmail.com)

2 Doutora em Educação, professora adjunta da Universidade Federal do Recôncavo da Bahia UFRB rosildaarruda@gmail.com
} 
constituye en la manifestación más clara del reordenamiento de ese nivel de enseñanza, analizando uno de sus efectos representativos: la implementación de un nuevo modelo de carreras de grado en las universidades federales, llamados bachillerato interdisciplinarios.

Educación superior brasileña, Sistema de enseñanza superior brasileño, Bachillerato interdisciplinarios.

\section{Introdução}

Contrariamente às histórias das Américas Espanhola e Inglesa que, ainda no período colonial tiveram acesso à educação superior, o Brasil aguardou até o final do século XIX para que as primeiras instituições científicas e culturais deste nível surgissem motivadas pela vinda da Família Imperial ao país.

A partir da proclamação da Independência em 1822, aumenta o número de escolas superiores, no formato de unidades isoladas com foco na formação profissional. Entre 1808 e 1882 ocorreram tentativas de criar as primeiras universidades no Brasil, mas que sequer tiveram seus projetos debatidos nos órgãos de representação política existentes no país. Nesta época, a abolição da escravatura tomava a atenção integral dos parlamentares e os «pareceres e projetos de reforma da instrução de Rui Barbosa entraram a dormir no 'sono donde passaram ao mofo e à traçaria dos arquivos' palavras dele mesmo». (MACHADO, 2002, p.153).

Em 1891, mesmo com a chegada da "República", a Constituição omite-se em relação ao compromisso do governo com a educação universitária. Entre 1909 e 1912 surgem as primeiras universidades no Brasil: a Universidade de Manaus (1909) e a do Paraná (1912) (FÁVERO, 2006). Anos depois, em 1920 é criada oficialmente a primeira universidade da capital do país, hoje Universidade Federal do Rio de Janeiro - UFRJ. Apenas em 1931, com a promulgação do Estatuto das Universidades Brasileiras, a universidade surge como instituição formal. Após a Revolução Constitucionalista de 1932, ocorrida em São Paulo, foram criadas, em 1934, a Universidade de São Paulo (USP), a Universidade de Porto Alegre (UPA) e em 1935 a Universidade do Distrito Federal (UDF).

Este é um período de desenvolvimento político e econômico para o país muito especial. Os efeitos da abolição da escravatura levam o Brasil a «mobilizar 
os homens em torno da modernização da sociedade, ensinando-Ihes o valor do trabalho» (MACHADO, 2002, p. 153) e com o processo de imigração, logo em seguida, essa preocupação vai desaparecendo. O percurso em tela nos leva a questionar que modelos de ensino e pesquisa foram herdados quando da implantação dessas primeiras instituições e quais consequências foram percebidas, tendo em vista este cenário social apresentado? Na tentativa de identificar algumas respostas, destacamos três correntes de pensamento que marcaram esta história: a francesa e a alemã, no princípio e a corrente norteamericana no período mais contemporâneo.

\section{Contributos e influências dos primeiros modelos de educação superior}

É consenso na literatura - Anastasiou (1998), Paula (2002), Morosini (2006), Almeida Filho e Santos (2008) - que as Universidades da América Latina e, não obstante as brasileiras, iniciaram sua história com a forte influência dos modelos europeus, prioritariamente o francês e o alemão. Justificada pelo contexto social da época, as primeiras faculdades brasileiras tinham a finalidade de formar as pessoas para o domínio técnico e profissional como maneira de enfrentar o subdesenvolvimento. Não por acaso, os estrangeiros indicados para lecionar nas primeiras universidades, eram franceses. Com isto, se instalava o modelo napoleônico que se consistiu por escolas isoladas de cunho profissionalizante e com grande centralização estatal. Nesse modelo, a pesquisa não é atividade nuclear da universidade, havendo dissociação entre universidades que se dedicam fundamentalmente ao ensino, e "grandes escolas" voltadas para a pesquisa e formação profissional de alto nível.

O napoleônico foi um modelo que se caracterizou por uma estrutura universitária composta como federações de faculdades e de escolas de caráter profissionalizante. Com uma organização eminentemente profissionalizante, os cursos ou faculdades se centravam na finalidade de formar os burocratas que atuariam nos quadros administrativos do Estado. Fruto dessa influência, a universidade se imbuia dos mesmos ideais autoritários impostos pelo governante à sociedade civil. Esta, por sua vez, não tinha clara consciência da situação, até 
porque a educação não estimulava a crítica, pelo contrário, servia mais como doutrinação, mantendo os interesses do governo e das elites. Nos dias atuais, este modelo, segundo Anastasiou e Alves (2004), ainda se materializa em currículos universitários desenhados em grades com privilégios aos prérequisitos, separando as disciplinas básicas das profissionalizantes que de acordo com o princípio da racionalidade, distancia teoria da prática.

Contrapondo-se a esse modelo, o humboldtiano compreendeu a concepção humanista-idealista-humboldtiana e emergiu quando a Alemanha, acometida pelos acontecimentos da Revolução Francesa e pelo domínio napoleônico do início do século XIX, criou universidades novas para equilibrar a perda de instituições que passaram para territórios estrangeiros e para unificar a nação. Tais universidades, por não estarem presas à tradição anterior, se adaptaram às novas exigências sociais e intelectuais.

Do modelo humboldtiano tem-se a herança de uma concepção de universidade formadora de «elites dirigentes com base na constituição de uma Faculdade de Filosofia, Ciências e Letras como órgão central de ensino superior e com consequente ênfase na formação científica de cunho humanista, não pragmático» (PAULA, 2002, p. 151).

Nessa concepção alemã tem-se, como fundamento, a ênfase na importância da pesquisa na universidade e a indissociabilidade entre ensino, pesquisa e uma formação com perspectiva geral, científica e humanista, com enfoque na totalidade e universalidade do saber. Politicamente, seu caráter é corporativo e deliberativo, gozando de liberdade de ensino e pesquisa nas primeiras décadas de funcionamento. A preocupação com a constituição da nacionalidade se deu com base numa perspectiva liberal elitista, com maior autonomia da universidade diante do Estado desembocando numa concepção mais idealista e acadêmica, e menos pragmática de universidade (PAULA, 2002). Ao longo do tempo, essa concepção sofreu uma série de modificações e desvios, dentre os quais se destaca a diminuição considerável da autonomia e da liberdade acadêmica.

Sobre o compromisso social da universidade, o primeiro modelo a tensiona para a formação de burocratas para exercerem funções de Estado, o que fica 
notório o seu entrelaçamento aos interesses do Estado, inclusive na preparação de seus quadros, os quais deveriam seguir rigorosamente a orientação do governo, do poder instituído, deixando em segundo plano, os interesses da sociedade, da nação e dos segmentos médios e pobres da população, uma vez que só as elites tinham acesso a esse nível de ensino. O contrário do que o modelo alemão sustentava: a necessidade de sua plena independência financeira e administrativa do Estado. Pela influência humboldtiana, o que conta é a convicção de que toda forma de pretensão econômica social ou estatal deve ser rechaçada e, nesse modelo, a investigação científica, a formação humana e as ciências aplicadas ficaram fora da universidade (PAULA, 2002).

Ou seja, no entendimento de como a universidade pode ser uma instituição a serviço do Estado, há oposição entre os dois fortes modelos que influenciaram a estruturação das primeiras universidades brasileiras. Enquanto o projeto implementado no modelo napoleônico impunha à universidade todos os controles do Estado para que ela cumprisse as atividades traçadas por esse, garantindo os efeitos da ação esperada com vistas ao seu fortalecimento, o modelo humboldtiano desconsiderava o nacionalismo estreito, o protecionismo, o utilitarismo e o positivismo que guiam os poderes públicos em matéria de ciência.

Ao herdar o modelo francês, fortalecemos o espírito cartesiano nas ciências naturais, humanas e no mundo político e moral, uma vez que a universidade napoleônica era cartesiana, tecno-profissional e guia crítico-espiritual do Estado (moderno) e reafirmando uma universidade estatal de ensino, regida pelo interesse do Estado para seu o progresso econômico-político e da divulgação da língua nacional.

Quanto ao modelo alemão, herdamos principalmente a presença da pesquisa e da autonomia na constituição da universidade e por elas os demais âmbitos se estruturaram. Uma pesquisa que enfatiza que a organização interna das instituições científicas superiores tem o dever de incentivar a própria atividade de pesquisa; por isso, deve ser uma colaboração livre, isto é, sem ter que obedecer a uma finalidade prévia ou externa, livre inclusive de posicionamentos e defesas políticas. Em algumas instituições o fazer pesquisa 
permanece centrado em áreas específicas e, até mesmo, em alguns professores por inúmeros fatores, como os ideais do projeto científico e tecnológico do país e a importância que a área assume em períodos distintos, as oportunidades de financiamento, a relevância da área para determinada instituição, a presença de laboratórios, estrutura, equipamentos e pessoal técnico de apoio, com a formação do professor em nível de doutorado e seu interesse por pesquisa, dentre outros (PAULA, 2002).

Durante o período que ficou conhecido por Nova República (1945-1961), surgem diversas universidades públicas federais, distribuídas nas respectivas capitais de cada unidade da federação, e também universidades confessionais, oportunizando a expansão das matrículas. Estas universidades instituídas reuniam os cursos superiores da ocasião, criando vários outros na época e posteriormente. As heranças francesas e alemãs se fundem a outras propostas do Estado brasileiro, moldando-se aos mecanismos de nação impostos na época.

A esse respeito, importa destacar uma destas propostas do Estado brasileiro, marcadamente influenciado pelo modelo americano e tratou-se de contribuição vital para este campo: o novo modelo de educação superior proposto por Anísio Teixeira em 1960. Persistindo em ideais pregressistas e com apoio político, em 1961, Anísio institui a Universidade de Brasilia - a UnB - como uma tentativa de adaptar o modelo norte-americano à realidade brasileira menos especializada, mais carente de recursos e indissociando o saber prático. Gratuidade e igualdade eram princípios filosóficos de base dessa universidade. Os programas de ensino eram baseados em ciclos de formação geral e, grandes áeras de conhecimento organizavam centros, substituindo, dessa forma, as faculdades superiores. Tal modelo se constituiu num referencial para as demais universidades.

Seu ideal de universidade se opunha às ideias de escolas superiores isoladas, pois defendia que apenas um referencial de conhecimento integrado seria capaz de promover uma educação para a cidadania e para a democracia. Este projeto, entretanto, durou pouco, pois uma das primeiras medidas decorrentes do Golpe Militar em 1964, foi a tomada da UNB desmoronando seu 
projeto com demissão do quadro de professores e alteração da proposta administrativa e curricular (ALMEIDA FILHO \& SANTOS, 2008).

Neste mesmo período, o modelo norte-americano passa a ser referência para a reforma na época instituida pela reorganização millitar do ensino superior (Lei 6.540/1968) o que marca também na história da constituição da universidade brasileira a seletividade acadêmica e social como referência para as mudanças.

Das contraditórias consequências para o ensino superior brasileiro, decorrentes dessa reforma tem-se por um lado, a modernização de uma fatia significativa das universidades federais, a revogação das cátedras vitalícias, a progressão da carreira docente e a expansão da pós-graduação. Do outro lado, segundo, Florestan Fernandes (1975) é momento do surgimento do ensino privado e, com ele, o isolamento, a transmissão de conhecimentos de natureza estritamente profissionalizante e separação formal do ensino e da pesquisa.

Uma característica fortemente associada a este modelo era uma formação voltada para as exigências da sociedade capitalista estritamente de acordo com o momento atual que o país atravessava para ultrapassar o subdesenvolvimento. A funcionalidade, praticidade e a técnica eram privilegiadas em detrimento da intelectualidade e do humanismo, aspectos importantes na formação científica e filosófica dos estudantes (FERNANDES, 1975).

Naturalmente que essas concepções não foram exclusivas, mas talvez determinantes para compor a história da educação superior brasileira marcada pela importação de modelos pedagógicos, curriculares didáticos e administrativos desde os seus primórdios. Podemos afirmar que a universidade clássica e seus modelos principais: napoleônico, hierárquico e conduzido ao alto e o humboldtiano, ligando à pesquisa e à formação, privilegiando a autonomia, não desapareceram, mas, talvez possamos afirmar que por ela estar imersa em um novo sistema mais amplo, muito mais variado e logo, mais complexo, reclama por um novo modelo.

Esta amplitude se justifica quando notamos as inúmeras conexões que se estabelecem hoje entre o mundo do trabalho e as universidades, e começam, inclusive, bem mais cedo (um estudante de graduação amplia sua percepção através do estágio, por exemplo, desde o segundo semestre do curso). Mais 
variado e complexo, pois, nestas conexões, as relações são diversas e muito mais ricas, sobretudo no campo dos registros científicos, nas novas relações entre os setores públicos e privados, no crescente número e variedade de empresas, associações, organizações não governamentais que são criadas dentro da estrutura das universidades e fora delas.

Pode-se deduzir que alguns dos atuais impasses vividos pela universidade no Brasil necessariamente estão relacionados à sua própria história e aos modelos herdados. Pelos estudos (PAULA, 2002; MOROSINI, 2006; TEIXEIRA, 1968), tem-se claro que ela foi criada não para atender às necessidades fundamentais da realidade da qual era e é parte, mas considerada como um bem cultural destinado a uma minoria. Produção essa que deveria procurar responder às necessidades sociais mais amplas e ter como preocupação tornar-se expressão do real, compreendida como característica do conhecimento científico.

Um dos efeitos mais perceptíveis destas reformas centra-se na composição curricular linear e hierarquizada da educação universitária brasileira decorrente dos modelos de formação nas universidades europeias, em especial àquelas até aqui estudadas. No final dos anos 60 as estruturas universitárias acadêmicas muito sofreram com a reforma imposta pelo governo militar e, em seguida, com a abertura do mercado ao setor privado de ensino tendo como resultado, segundo Almeida Filho e Santos (2008), uma universidade brasileira submetida a um potente viés profissionalizante, com uma concepção curricular simplista, fragmentadora e afastada dos saberes e das práticas de transformação da sociedade.

\section{Características do sistema de ensino superior brasileiro pós LDB 9394/96: avanços e recuos}

A promulgação da primeira Lei de Diretrizes e Bases da Educação Brasileira, Lei no 4.024/61, mesmo discursando sobre a possibilidade de flexibilização no ensino superior reforçou, na prática, o modelo tradicional vigente, mantendo as cátedras vitalícias e a supremacia do ensino sobre a pesquisa, uma vez que era uma época de repressão e silenciamento total, fruto 
do regime ditatório militar. Em 1971, é promulgada a lei № 5.692 de 11 de agosto de 1971 que fixa diretrizes e bases para o ensino de $1^{\circ}$ e $2^{\circ}$ graus - que hoje correspondem aos níveis da educação básica não se referindo, portanto, aos interesses da educação superior.

É a partir da Lei de Diretrizes e Bases da Educação Nacional LDB 9.394/96 que os debates para o ensino superior são retomados. Em primeiro lugar, o estabelece como um nível de ensino da Educação e, define, no Capítulo IV finalidades, modalidades de cursos e programas, campos de abrangência e expansão. Com um caráter inovador, estabelece mecanismos de controle e regulação da qualidade para este nível de ensino por meio da introdução de programas de avaliação institucional.

Dentre todas as finalidades da educação superior, previstas no art. 43 da referida lei, torna-se importante destacar o inciso I: «estimular a criação cultural e o desenvolvimento do espírito científico e do pensamento reflexivo", uma vez que o estímulo ao pensamento reflexivo parece-nos reclamar por uma formação em diferentes áreas, minimamente, a cultura, ciência e a tecnologia. Por conseguinte, esta articulação pode contribuir na medida em que se promove inter e intra-área. Não obstante, o incentivo à investigação é proposto sob a perspectiva do desenvolvimento da ciência aliado à arte e à tecnologia e o conhecimento é caracterizado com uma tríplice face: cultural, científica e técnica. O que percebemos é que, repetidamente, esse tripé surge como vértices ligando, unindo, aproximando as múltiplas formas de entendimento da vida e do homem. Com isso, complexidade, integração, rede de relacionamento dentro das escolas superiores - sejam elas de qualquer modalidade ou esfera - tornam-se urgências na definição do currículo, nas práticas de trabalho e nas relações. Parece-nos aqui que a concretização dessas finalidades no âmbito do ensino se dá por meio de uma forte tendência em dialogar e, acima de tudo, flexibilizar os diversos elementos que compõem esses espaços acadêmicos, quer no nível administrativo, pedagógico ou financeiro.

Para dar conta dessas finalidades, esta mesma Lei estabelece, no art. 45, que a educação superior «será ministrada em instituições de ensino superior, públicas ou privadas, com variados graus de abrangência ou especialização». E, 
conforme sua organização acadêmica, definidas pelo Decreto nํ⒌773, de 9 de maio de 2006, podem ser compreendidas como Universidades, Centros Universitários, Faculdades e, mais recentemente, em Institutos Federais. Em seu artigo 52, a LDB 9.394/96 compreende as Universidades como Instituições pluridisciplinares, públicas ou privadas de formação de quadros profissionais de nível superior, que desenvolvem atividades regulares de ensino, pesquisa e extensão e de domínio e cultivo do saber humano.

E dentro delas, respectivos cursos e programas: sequenciais, graduação bacharelado ou licenciatura, pós-graduação - mestrados e doutorados - e de extensão, direcionados tanto para necessidades específicas quanto para público diferenciado.

Desses cursos, a graduação ainda é a mais procurada. Destinada a candidatos com o ensino médio concluído e que tenham sido classificados por meio de processo seletivo, habilitam-nos, ao seu final, a exercerem a profissão escolhida e, portanto, ingressarem no mercado de trabalho com o título de bacharel, licenciado ou tecnólogo.

Os cursos sequenciais ofertados em diversas áreas do conhecimento são destinados a um perfil que opta por menor tempo de duração na educação superior. Os cursos de extensão nascem a partir da urgência de se discutir temáticas extracurriculares e são ofertados ao grupo interno e externo da instituição, os quais, em geral não exigem pré-requisitos para a sua entrada.

Em nível de pós-graduação, as instituições de ensino superior brasileiras ofertam uma ampla gama de opções em especialização, mestrado profissional, mestrado acadêmico ou doutorado. Apenas universidades e Centros Universitários detêm autonomia para criar e implantar cursos e programas de mestrado e doutorado (stricto sensu). Já nas demais instituições (faculdades, faculdades integradas, IFEs), a implantação desses cursos está sujeita à autorização do Ministério de Educação.

Na sequência, os estudantes podem avançar seus estudos optando por dois tipos de mestrados, o profissional e o acadêmico, que no Brasil, são concluídos geralmente em dois anos. O primeiro tenta responder a uma necessidade socialmente definida de capacitação profissional em que evidencia 
estudos e técnicas diretamente voltadas ao desempenho de um alto nível de qualificação profissional, e o segundo, volta-se ao desenvolvimento da pesquisa acadêmica e confere habilidades para docência no ensino superior. Já os cursos de doutorado são desenvolvidos num período de quatro anos, aproximadamente, e sua conclusão está condicionada à apresentação de uma tese inédita sobre determinado assunto.

Para esse conjunto de modalidades e níveis que se encontra estruturado o ensino superior brasileiro, a Lei $n^{\circ}$ 9.394/96, garantiu mais autonomia às universidades. Esta garantia significa por um lado, um avanço no processo da descentralização concedendo flexibilidade à gestão das universidades mesmo sendo possível que a União as descredenciem. Por outro lado, Tavares (1998, p. 65), defende que esta mesma autonomia pode significar também, na prática «a inviabilização de um paradigma de universidade voltada aos interesses de setores da população historicamente marginalizados» quando, por exemplo, a autonomia financeira preconizada rejeita qualquer outra concepção de universidade que não esteja dentro dos referenciais definidos pelo governo central.

Ainda assim, o art. 53ํำ da Lei prevê o exercício da autonomia universitária a partir da garantia de várias atribuições dela decorrentes. No âmbito do ensino, cabe destacar a liberdade para a fixação de currículos de cursos e programas desde que de acordo com as diretrizes gerais - e liberdade para definir e estabelecer programas, projetos de pesquisa, base legal - estatutos até regimentos internos. Nesse sentido, à medida que as políticas se instalam, a sua consolidação passa a reclamar por mudanças e reformas profundas, tanto no ambiente pedagógico como na forma de perceber a universidade pública.

Não é por acaso que a relação indissociável entre ensino, pesquisa e extensão constitui alicerce substancial da universidade, um princípio para o exercício desta reclamada autonomia. A própria Constituição Federal de 1988 em seu Art. 207 anuncia que o pleno gozo de autonomia didático-científica, administrativa, de gestão financeira e patrimonial implica na realização das atividades acadêmicas alicerçadas nesse tripé. 
Esse princípio se constitui um dos temas fundamentais para 0 desenvolvimento de políticas educacionais que se sucederam ao longo dos últimos vinte anos no país e corrobora para o ingresso e o firmamento da interdisciplinaridade nos estudos relativos ao processo de ensino e aprendizagem na educação superior, sobretudo nas universidades. A partir dos debates da indissociabilidade é que a interdisciplinaridade é apresentada como uma condição para que este projeto político se efetive, sob várias perspectivas.

A indissociabilidade entre o ensino, a pesquisa e a extensão, assume lugar, ainda que de forma menos explícita, na Lei № 9.394/96, quando as finalidades da educação superior pressupõem a investigação científica a partir do trabalho de pesquisa, o ensino como forma de comunicação do saber e a extensão como mecanismo de divulgação dos resultados da pesquisa cientifica concebidas pela instituição.

Desse modo, entender essa indissociabilidade ultrapassa a mera questão teorética ou legal, mas essencialmente, perceber e compreender questões epistemológicas, políticas e pedagógicas vinculadas a interesses e a projetos nacionais de educação ao longo do tempo.

O termo indissociável nos remete a pensar em algo que não se pode separar, desunir. Esta condição reduz as distâncias entre as atividades acadêmicas e a sociedade conferindo-Ihe um significado social, uma vez que pressupõe projetos comuns entre si tendo em conta o que é relevante para a maioria da sociedade. Não obstante, este tema também contorna debates relativos à flexibilização curricular e à busca da unidade da teoria e da prática nas universidades.

Apesar disso, o que tem sido percebido nas últimas décadas é o contrário. Ensino, pesquisa e extensão têm caminhado em sentidos distintos, muitas vezes opostos, demarcando o seu afastamento. Essa situação reforça a ideia de que essas obrigações não são possíveis de se complementar. É neste enquadramento $e$, à frente de alguns desafios, que se coloca $a$ interdisciplinaridade como forma de contribuir para a superação desse tipo de prática. 
Quanto ao ensino, dentre os princípios em que deverá ser ministrado, destacamos «valorização da experiência extraescolar e vinculação entre a educação escolar, o trabalho e as práticas sociais» (art. $2^{\circ}$ ). Será prioritariamente por meio dele que a educação superior disseminará o saber historicamente instituido.

Quanto à pesquisa, está presente no conjunto das atribuições asseguradas à educação superior além de ser destaque nas finalidades para este nível de ensino vez que é, através dela, que o homem compreenderá o meio em que vive e perceberá suas relações encontrando - ou não - resposta a questões mais amplas de ordem social. Ademais, esta mesma lei recomenda que a extensão tenha dentre outras finalidades, a de divulgar os resultados das pesquisas geradas na instituição. Tal condição confere à extensão um lugar privilegiado neste tripé, pois deste lugar se estabelece a ligação entre a universidade e a sociedade ratificando o seu engajamento social.

Reunidos, esses três eixos tentam dar conta de uma visão de universidade «pautada em novos paradigmas, que envolve o respeito à ética, à diversidade cultural e à inclusão social como seus princípios e suas referências» (BRASIL, 2006, p. 40). Com essa compreeensão, a prática de envolver os diversos segmentos sociais - privilegiados ou excluídos - amplia as suas atribuições que, para além de produzir conhecimento novo e contribuir para o avanço da cultura, da ciência e da tecnologia deverá voltar-se para a «interdisciplinaridade, vista na perspectiva da estruturação dos problemas sociais e do desenvolvimento regional e local» passando então a compreender o trabalho científico mediante sua relevância social (BRASIL, 2006, p. 41).

O discurso em tela prevê que a produção do conhecimento científico esteja em constante sintonia com questões sociais urgentes, o que consiste em rever métodos de pesquisa, ensino e extensão prezando, sobretudo, os conhecimentos do senso comum e a interdisciplinaridade uma vez que uma única disciplina não consegue explicá-las.

Prevê também uma preparação profissional em que estejam circunscritas habilidades aliadas à flexibilidade, constante mudança e relativização, caso contrário, essa formação torna-se, em pouco tempo, obsoleta. Para tanto, a 
pesquisa e a extensão são indispensáveis uma vez que contribuem numa formação do estudante para além da técnica chegando ao âmbito social e político desenvolvendo a criticidade.

Além disso, forças externas, exigências da sociedade, novas concepções quanto ao papel da universidade abrem espaço para se pensar num cenário em que a indissociabilidade entre ensino, pesquisa e extensão seja uma prática concreta de modo a tornar o conhecimento produzido acessível a toda a sociedade. Porém, até então, desarticulação e fragmentação são caraterísticas permanentes na atual conjuntura da educação superior quando esse tripé está em causa não refletindo o previsto em lei. Ações governamentais são pensadas com vistas ao enfrentamento de várias questões além das que citamos até aqui, demarcando um novo tempo para as políticas na educação superior, um tempo de uma universidade que congregue tais expectativas.

\section{Configurações da educação superior sob o ponto de vista legal}

Lançado oficialmente em março de 2007 o Plano de Desenvolvimento da Educação - PDE dispõe de 29 (vinte e nove) ações do Ministério da Educação e compõe o conjunto de medidas governamentais do Programa de Aceleração do Crescimento - PAC, com vistas ao crescimento do país. Nesse plano, foram inscritas cinco ações para tratar da educação superior com os seguintes focos para: a facilitação de acesso ao crédito educativo, promovendo mais oportunidades de acesso ao estudante de comprovada baixa renda; a valorização do profissional qualificado; novas contratações de professores em universidades federais; o aumento do número de vagas com a expansão universitária e a proposta de acessibilidade na educação superior.

Neste cenário analisamos, em especial, o contexto da reestruturação da arquitetura acadêmica da qual emergiu uma nova modalidade de cursos: os Bacharelados Interdisciplinares como resposta para o atendimento da meta, «a elevação gradual da taxa de conclusão média dos cursos de graduação presenciais para noventa por cento e da relação de alunos de graduação em 
cursos presenciais por professor para dezoito, ao final de cinco anos, a contar do início de cada plano» (BRASIL, 2007, p. 4).

Para o atingimento dessa meta foi projetado, em 2007, o Programa de Apoio a Planos de Reestruturação e Expansão das Universidades Federais REUNI. Na sua esfera, muitos pesquisadores se debruçam em analisar as consequências e os desafios postos à gestão universitária a partir desse Plano, dos quais mencionamos, p. Catani, Lima e Azevedo (2008) e Almeida Filho e Santos (2008).

Uma parte destes pesquisadores defende o REUNI especialmente pela possibilidade de melhor desenvolver atividades acadêmicas, notadamente, aquelas relacionadas à mobilidade, atualização na composição curricular, e novas modalidades de graduação. Outra parte critica por compreendê-lo como um caminho para a subserviência das universidades ao governo federal e, consequentemente, uma ameaça à qualidade da produção científica. Outro ponto de crítica reside no baixo repasse que o governo federal prevê para esta reestruturação, acarretando em implantações de laboratórios e bibliotecas, por exemplo, sem a devida infraestrutura nem manutenção.

De acordo com Catani, Lima e Azevedo (2008, p. 23), «o REUNI é um programa de reforma das IFES acoplado a um plus de financiamento para aquelas universidades que a ele aderirem». Esse conjunto de condições é uma forma de estimular a concorrência entre as universidades federais. Em outras palavras, sugerem que o REUNI configura uma disputa de regularidade e de busca de identidade ao referencial de universidade recomendado pelo MEC, uma vez que este programa estabelece a condição do cumprimento das metas para a liberação de financiamentos.

Embora a universidade passe a integrar novo traço de organização social marcada pela operacionalização, produtividade e flexibilidade distanciando-se da universidade como instuitição social, reconhecida pela sua capacidade de produzir conhecimento com liberdade e espírito crítico (CHAUí, 2001), este programa tem sido um dos instrumentos para a operacionalização das novas diretrizes na universidade pública com uma franca adesão. 
Basicamente, o centro das atenções desse plano gira em torno de dois argumentos. O primeiro trata da pouca oferta de vagas nas instituições públicas o que acaba direcionando o estudante para o setor privado que, segundo as mesmas diretrizes, encontra-se em total esgotamento. O segundo argumento refere-se às heranças antigas do regime de formação profissional que estão ultrapassadas para as atuais exigências do mercado de trabalho.

Em sua proposta, os objetivos foram focados na ampliação do acesso e permanência na educação superior, na inovação acadêmica aliada à integração dos diferentes níveis de ensino, na otimização e aproveitamento dos recursos humanos e infraestrutura das instituições federais de educação superior. Parecenos que a proposta de rearquitetura acadêmica dos cursos de graduação se destaca das demais intenções do REUNI, como veremos a seguir.

O Programa em tela compreende de seis dimensões: (i) a Ampliação da Oferta de Educação Superior pública que implica no aumento de vagas de ingresso, especialmente no período noturno, na redução das taxas de evasão e na ocupação de vagas ociosas. (ii) a reestruturação acadêmico-curricular que consiste na revisão da estrutura acadêmica buscando a constante elevação da qualidade, a reorganização dos cursos de graduação e a diversificação das modalidades de graduação, preferencialmente com superação da profissionalização precoce e especializada; Implantação de regimes curriculares e sistemas de títulos que possibilitem a construção de itinerários formativos; e Previsão de modelos de transição, quando for o caso. (iii) a renovação pedagógica da Educação Superior compreende a articulação da educação superior com a educação básica, profissional e tecnológica e a atualização de metodologias (e tecnologias) de ensino-aprendizagem bem como a previsão de programas de capacitação pedagógica, especialmente quando for o caso de implementação de um novo modelo. (iv) o Suporte da pós-graduação ao desenvolvimento e aperfeiçoamento qualitativo dos cursos de graduação compreende na articulação da graduação com a pós-graduação. (v) 0 compromisso social da instituição prevê políticas de inclusão, programas de assistência estudantil e políticas de extensão universitária. E (vi) a mobilidade intra e inter-institucional compreende na promoção da ampla mobilidade 
estudantil mediante o aproveitamento de créditos e a circulação de estudantes entre cursos e programas, e entre instituições de educação superior. (BRASIL, 2008)

Mesmo com seu término em 2012, sua natureza tem repercutido, ainda hoje, na prática de algumas instituições. A título de exemplo, temos a adesão do programa Universidade Nova e em decorrência, a criação dos chamados Bacharelados Interdisciplinares que, nas diretrizes do Programa são reconhecidos como uma, dentre outras «modalidades ou formas de organização curricular da graduação» (BRASIL, 2007, p. 26) como possibilidade de materialização dos ideais contidos para uma nova universidade. Tipo de formação que passaremos a discutir a seguir.

\section{Bacharelados interdisciplinares - BI}

O I Seminário Nacional da Universidade Nova ocorrido em dezembro de 2006 marca o início oficial das discussões relativas à reestruturação da arquitetura acadêmica da educação superior no Brasil. Na época, reuniram-se representantes de 57 (cinquenta e sete) Instituições Federais do Ensino Superior (Ifes) e do Ministério da Educação - MEC. O professor Naomar de Almeida Filho na oportunidade, reitor da UFBA, foi um dos idealizadores desse projeto com grandes contribuições do Professor Boaventura de Sousa Santos.

Antes de pormenorizá-lo, porém, é interessante relatar, brevemente qual o contexto de base do projeto Universidade Nova. Almeida Filho e Santos (2008) revela um percurso singular nesta linha do tempo em que os projetos Universidade Nova e UFBA Nova se convergem e fundem. É no encontro da Associação Nacional dos Dirigentes das Instituições Federais de Ensino Superior - ANDIFES, em agosto de 2006, que ele apresenta, ao Conselho Pleno dessa associação, esboços do projeto de uma UFBA Nova o qual teve muita receptividade e apoio de vários reitores a seu favor como uma proposta viável também para outras universidades. Com o engajamento de vários reitores em uma rede de discussão, no mesmo ano, o projeto é apresentando à ANDIFES, desta vez, como o projeto da Universidade Nova. Dai ficar evidente a fusão entre os projetos da Universidade Nova e da UFBA Nova. 
Desse encontro, resulta o Manifesto da Universidade Nova, elaborado pelos Reitores de Universidades Federais Brasileiras pela reestruturação da Educação Superior no Brasil demonstrando a emergência em se «consagrar um novo paradigma de universidade: contemporâneo com os destinos do mundo; afinado com o espírito de época; comprometido com as necessidades do desenvolvimento nacional e socialmente inclusivo» (MANIFESTO, 2006, p. 5). Este documento ratifica os argumentos apresentados pelo REUNI e aparece reproduzido no Projeto da Universidade Nova como princípios, orientações e encaminhamentos para o enfrentamento da questão em nome de uma nova universidade.

Expõem as deficiências postas na atualidade para as universidades que vão desde aos equívocos presentes nas diversas interpretações da sua função social, passando pelos efeitos nefastos do modelo tradicional vigente com paradigmas superados até a necessidade de vivificar a autonomia universitária. Ratificam fundamentos para a educação universitária dentre eles a articulação entre ensino pesquisa e extensão, por meio da inovação, do desenvolvimento científico e tecnólogico. E indicam estratégias no processo de reforma com destaque para a flexibilização e racionalização da formação profissional por meio da revisão dos currículos e projetos acadêmicos e, igualmente, facultar aos estudantes experiências interdisciplinares, formação humanistica, estímulo à criativade e capacidade crítica.

Dada as suas características, é possivel afirmar que o Projeto Universidade Nova tem um referencial histórico que se reporta à década de 1930 quando se levantou debates sobre uma nova concepção de universidade tendo, na liderança, Anísio Teixeira. Citado por Almeida Filho e Santos (2008), o projeto da Universidade Nova se inspira conceitualmente em Anísio Teixeira na medida em que para ele, a escola pública era "a máquina que prepara as democracias" e o lugar em que o diálogo e a participação no processo educacional são pressupostos fundamentais.

O mesmo autor apresenta argumentos a partir de trechos retirados do projeto de lei que institui a Universidade de Brasilia - UNB, como possíveis elementos conceituais que convergem integralmente com a proposta da 
Universidade Nova: a formação universitária numa perspectiva de unidade orgânica, aliada a uma preparação científica e cutural que antecede seu ingresso nos cursos profissionalizantes em órgãos universitários que não pertencem a nenhuma faculdade, mas ao contrário, servem a todas elas.

Além disso, a possibilidade de articulação entre os bacharelados, a educação superior com estrutura modular por ciclos de formação, tendo uma etapa inicial na formação universitária de caráter geral, são elementos de similitude com as propostas anisianas para a UNB.

Ao citar articulação dos saberes, relação espaço-tempo, hiperconectividade, pensamento complexo, multi-inter-trandisciplinaridade, paradigmas alternativos de formação como «valores filosóficos, metodológicos e pedagógicos da contemporaneidade», Almeida Filho e Santos (2008, p. 247) trazem outro aporte teórico-conceitual para a idealização da Universidade Nova: Milton Santos e a Geografia Nova. Tanto nesta proposta quanto na anisiana, a formação universitária em questão defende e prioriza a emancipação crítica de sujeitos e saberes a partir do reconhecimento desses valores em detrimento de qualquer forma de dominação.

E, com esse discurso, compromete-se a ultrapassar os pressupostos herdados dos modelos das clássicas escolas superiores que evidenciam contradições epstemológicas quanto à função da universidade eliminando distorções a ela inerentes em nome da emancipação pedagógica, curricular e, especialmente, política da universidade pública contemporânea.

A inspiração para este projeto de universidade também parte de análises outras no âmbito sócio-econômico e político tanto nacionalmente quanto internacionalmente os quais uma proposta dessa envergadura deve se lembrar. Como dizem, «precisamos avaliar as opções históricas possíveis neste momento, posto que os blocos político-econômicos já se definem, p. NAFTA, ALCA, União Europeia, novos atores como Mercosul, novas propostas como G4 (Brasil, África do Sul, Índia e China) » (ALMEIDA FILHO E SANTOS, 2008, p. 178). E ao tempo em que esses blocos são definidos, são demarcados espaços de predomínio de saberes no âmbito da educação superior e da produção cultural. 
Algumas pistas indicam que esse projeto também se inspirou em mais dois referenciais considerados por Almeida Filho (2008, p. 143) como «modelos de arquitetura curricular vigentes no mundo contemporâneo»: o modelo europeu unificado pelo processo de Bolonha - o MUE e o modelo norte-americano de college mais graduate schools - o MNA embora o mesmo autor reitere que a universidade Nova é livre de qualquer estratégia que a ponha em condição de submissão à internacionalização.

De fato, é possível perceber semelhanças quanto, por exemplo, à estrutura acadêmica e à organização dos níveis de ensino em ciclos. Tanto Bolonha quanto o projeto da Universidade Nova, propõem que os estudantes passem por etapas de escolaridade superior considerados ciclos priorizando, no seu primeiro momento, estudos gerais. A compreensão da universidade enquanto espaço privilegiado para uma formação profissional mais humanística e cultural, a conexão em distintas áreas e níveis de estudos, bem como a flexibilidade e mobilidade docente e discente, tratam-se de princípios políticos e conceituais que também aproximam aos ideais do Protocolo de Bolonha. Outra similaridade presente é o foco na empregabilidade, condição natural uma vez que fica demarcada cada vez mais a condição da universidade atender ao mercado de trabalho. Catani, Lima e Azevedo (2008, p. 27), trazem de modo crítico a compreensão de que «ao que tudo indica, o Brasil aprecia e admira as novidades europeias, embora se deixe levar pela força gravitacional dos EUA» ao adotarem o modelo americano para os $\mathrm{BI}$ sem, entretanto, a devida estrutura acadêmica e tecnológica que o mercado de trabalho exige das universidades.

Mesmo assim o projeto se constitui e, para a garantia da modularização da interdisciplinaridade, da progressão e da flexibilidade com vistas a assegurar a mobilidade intra e interinstitucional, é proposta uma estrutura curricular para o padrão Universidade Nova.

A estrutura do Programa Universidade Nova tem como fundamental mudança a implantação do regime de três ciclos de educação universitária reorientando, desse modo, a trajetória acadêmica dos estudantes que, ao ingressarem na universidade através do ENEM/Sisu, passam por três fases distintas, se assim desejarem «Primeiro Ciclo: Bacharelados Interdisciplinares 
(BI), propiciando formação universitária geral, como pré-requisito para progressão aos ciclos seguintes; Segundo Ciclo: Formação profissional em licenciaturas ou carreiras específicas; Terceiro Ciclo: Formação acadêmica, científica ou artística, de pós-graduação» (ALMEIDA FILHO \& SANTOS, 2008, p.200).

O Bacharelado Interdisciplinar - BI trata-se de um curso com terminalidade própria quando, então, o estudante poderá optar, após sua conclusão ou por avançar seus estudos partindo para o terceiro ciclo ou até mesmo encerrando sua cadeira de estudos neste primeiro ciclo e seguindo para o mercado de trabalho com uma formação em bacharel interdisciplinar em determinada área de conhecimento.

Em síntese, essa proposta sugere mudanças na forma de ingresso dos estudantes nas universidades federais, na composição, ordenamento e dinâmica curricular das graduações além da mobilidade acadêmica e interface com os diversos niveis: graduação e pós-graduação e respectivas modalidades. Estas mundanças passam a se concretizar, pouco a pouco com o reordenamento do currículo dos cursos profissionais e da pós-graduação; com a institucionalização dos Bacharelados Interdisciplinares nas universidades federais e com as novas possibilidades de processo seletivo.

Parece oportuno, antes de proceder ao estudo dos referenciais, destacar dois aspectos que nos levam a compreender que os BI estão circunscritos com especial relevo no movimento de reforma acadêmica proposto pelo REUNI. O primeiro trata-se de que este Programa induziu as «IFES a realizarem reestruturações da arquitetura acadêmica a fim de melhorar o processo formativo na graduação» (BRASIL, 2010, p. 2) e, a partir de então, propostas mais amplas de reordenamento curricular passam a compor a agenda dos debates na Educação Superior.

O outro aspecto consiste na defesa de que uma nova dinâmica social nos processos de produção e circulação do conhecimento tem reclamado por novas formas de profissionalização, novos modelos universitários reiterando a urgência em superar a visão fragmentadora do conhecimento sob a qual a atual arquitetura curricular das nossas graduações encontra-se acomodadas. 
Os Bacharelados Interdisciplinares são «programas de formação em nível de graduação de natureza geral, que conduzem a diploma, organizados por grandes áreas do conhecimento» (BRASIL, 2010, p. 24) e se caracterizam por uma trajetória formativa altamente flexivel quanto à composição curricular, baseada na interdisciplinaridade e mobilidade intra e interinstitucional. Constituem-se assim, como a etapa inicial dos estudos superiores quando serão desenvolvidas competências e habilidades voltadas para a autogestão da aprendizagem ao longo da vida atribuindo ao estudante plena autonomia.

É possivel perceber a concretização da dessas orientações em três contextos distintos: o primeiro, na organização de atuais cursos de $\mathrm{Bl}$ em áreas de concentração próximas a essas orientadas, a saber: Artes, Ciência e Tecnologia e Humanidades; o segundo, nas múltiplas oportunidades de experiências dos estudantes no cotidiano pedagógico; e o terceiro, na diplomação nas respectivas grandes áreas.

Diante dessa caracterização é possivel reconhecer duas perspectivas de caráter, inegavelmente, interdisciplinar, nos anos inicais do estudante da educação superior. Uma delas trata-se do investimento à formação geral alicerçado na multiplicidade cultural das mais variadas áreas, quer seja artística, científica, cultural ou tecnológica, ao tempo em que o aluno vai se reconhecendo diante do leque de possibilidades e ofertas de formação profissional na educação superior. A outra, na intenção pedagógica que investe na postura flexível do estudante voltado para o desenvolvimento e a vivência de práticas complexas consolidando uma formação baseada na interdisciplinaridade. Tendo em vista essa intenção é fundamental que a comunidade universitária tenha espaço e tempo adequados para atualizar constantemente as práticas educativas.

É então esperado que este profissional mobilize, com flexibilidade, conhecimentos, competências e habilidades gerais e específicas para responder às determinações do mundo do trabalho. Isto nos faz lembrar dos conceitos e práticas da interdisciplinaridade na dimensão interacional em que a comunicação de ideias, o intercâmbio e o desenvolvimento do pensamento sistêmico promovem, de certo modo, a flexibilidade. 
Pelo conjunto de competências que desenham o perfil profissional de um bacharel interdisciplinar, parece-nos existir mais um fio que une a proposta da Universidade Nova e dos Bacharelados Interdisciplinares à Declaração de Bolonha. É que tais competências derivam das originárias competências presentes no Projeto Alfa Tuning para a América Latina que, por sua vez, se inspira no Projeto Tuning do Processo Europeu de Bolonha. Almeida Filho e Santos (2008) admitem ainda que essa iniciativa teve como principal finalidade estrear formas de interação com as 62 (sessenta e duas) universidades latinoamericanas que participaram desse projeto - e também com universidades brasileiras - contribuindo para o desenvolvimento da qualidade por um lado e por outro, detectando competências relacionadas às profissões.

Em respeito às variações das estruturas e práticas de ensino, os referenciais nacionais declaram que cada instituição deve apresentar sua proposta preservando, naturalmente, elementos que garantam a interdisciplinaridade uma vez que este é o traço marcante dos BI. A diversidade na organização curricular deve estar presente nos projetos pedagógicos uma vez que se constituem ferramentas de consulta para que a comunidade projete esses ideais na prática.

Daqui em diante, cabe destacar que Almeida Filho (2008) apresenta as configurações dos Bacharelados Interdisciplinares como sendo pertencentes ao Projeto UFBA Nova. Então, é bom que se esclareça que o modelo ora proposto se definiu como um ponto de partida para que outras universidades consubstanciassem, do seu modo, os ideais preconizados de universidade neste novo século.

O curso tem duração prevista para integralizar os estudos em três anos como carga horária mínima de 2.400 horas. As modalidades previstas no Projeto UFBA Nova abrangem quatro grandes áreas do conhecimento: Artes, Humanidades, Ciência e Tecnologia e Saúde.

Este Projeto também introduziu o conceito de Área de Concentração (AC) como campos de formação ou campos do conhecimento multi ou interdisciplinares que se constituem de componentes, parte optativos e parte obrigatórios. Estas áreas são organizadas a partir de um conjunto coerente de 
estudos teóricos e aplicados que contribui para superar um perfil acadêmico encerrado em si mesmo.

Como resultado, a titulação se fará com a especificidade escolhida pelo estudante como: Bacharel em Ciência e Tecnologia, Área de Concentração em Ciências da Matéria, ou Bacharel em Saúde, Área de Concentração em Saúde Coletiva e assim sucessivamente.

Almeida Filho e Santos (2008, p. 202) destacam que os conceitos de Bloco e Eixos curriculares são a base estrutural do currículo «definidos como conjunto de módulos (cursos, disciplinas, atividades, programas, trabalhos orientados) ofertados aos alunos durante o período letivo».

A Formação Geral integraliza-se com uma carga horária mínima de 600 (seiscentas) horas - $25 \%$ do total dos três anos - e compõe-se de três eixos Eixo EL: das Linguagens (formação paralela e sequencial durante todo o programa) e Eixo ET: Interdisciplinar Temático (composto por dois blocos: Estudos sobre a Contemporaneidade e Formação nas Três Culturas) e Eixo El: Orientação profissional ou Integrador (sequência de módulos, blocos ou atividades de integração que articulem múltiplos conteúdos).

Os primeiros registros de $\mathrm{BI}$ no Brasil datam de quase dez anos. A Universidade Federal do Grande ABC - UFABC já vinha protagonizando o movimento de implantação de ciclos e bacharelados interdisciplinares antes mesmo da formalização da Universidade Nova e também da implantação dos referenciais orientadores, em 2008.

Neste modelo, a prática da universidade, sobretudo o ensino e a pesquisa, bem como a organização curricular dos cursos de graduação e pós-graduação se fundamentam na interdisciplinaridade. Seu projeto dispõe de um currículo por áreas do conhecimento com vistas tanto à possibilidade de ser tornarem referência acadêmica quanto à possibilidade de uma educação integral como princípio a ser seguido. Atualmente, a UFABC encontra-se com dois campi Santo André e São Bernardo do Campo contabilizando, em agosto de 2015, 12.433 alunos matriculados. Destes, 9.201 encontram-se distribuidos entre os três bacharelados interdisciplinares que oferta. Estes números conseguem 
traduzir os resultados positivos do projeto e a capacidade de alcance da universidade.

Em 2008, a Universidade Federal do Recôncavo da Bahia (UFRB) propõe o BI em Ciências da Saúde e, no ano seguinte, em Energia e Sustentabilidade; A Universidade Federal Rural do Semi-Árido (UFERSA) implanta o BI em Ciência e Tecnologia e a Universidade Federal de Alfenas conta com Ciência e Economia. A Universidade Federal da Bahia e a Universidade Federal dos Vales do Jequitinhonha e Mucuri (UFVJM) implantam em 2009 os Bacharelados Interdisciplinares, respectivamente, em Humanidades, Ciência e Tecnologia, Saúde e Artes e o segundo, em Humanidades e Ciência e Tecnologia. Em 2010, a Universidade Federal de Juiz de Fora (UFJF) lança o BI em Ciências Humanas e outro em Artes e Design.

Em 2011, a Universidade Federal do Oeste do Pará (UFOPA) implanta sete Bacharelados Interdisciplinares: Etno Desenvolvimento; Gestão Ambiental; Ciências e Tecnologia das Águas; Ciências Biológicas; Tecnologia da Informação; Ciências da Terra; Ciências e Tecnologia. Em 2012, chega a vez da Universidade Federal de São João Del Rey (UFSJ) implantar o Bl em Biossistemas. Em 2013, a Universidade Federal de Santa Catarina (UFSC) propõe o $\mathrm{Bl}$ em Mobilidade.

Registros recentes publicados na base de dados do Ministério de Educação - MEC anunciam que, das instituições superiores existentes nos 27 estados brasileiros, 53 em 16 estados cadastraram curso Interdisciplinar nas mais variadas modalidades. O gráfico seguinte revela esta distribuição entre as cinco regiões do Brasil. 


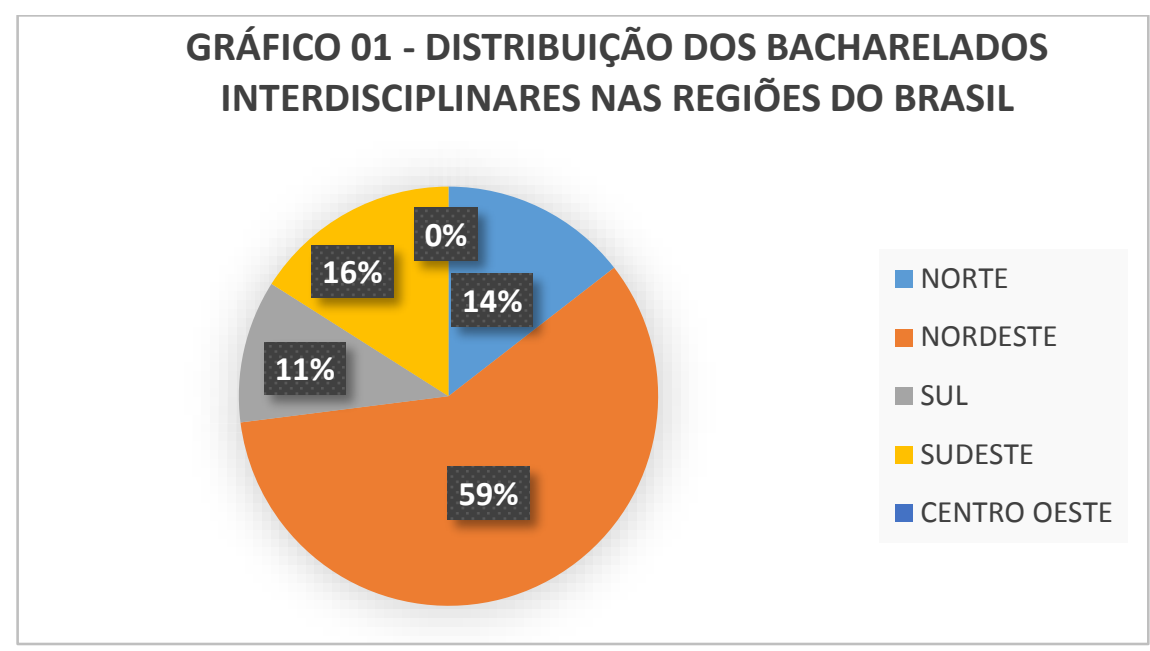

Fonte: Elaborado pelas autoras, dados do E-Mec, 2015.

A partir deste gráfico, é possível reconhecer uma maior concentração destes cursos nas regiões Sudeste, Norte e Nordeste do país. Entretanto, nestas regiões, três estados centralizam a oferta de acordo com o E-Mec: a Bahia com $37 \%$ dos cursos, o Pará com 12,5\% e Minas Gerais com 10,5\%, ou seja, mais de $50 \%$ dos cursos ofertados em todo o Brasil estão concentrados nestes três estados.

No conjunto dos 105 cursos cadastrados, quanto ao grau, contabilizam-se 60 (sessenta) bacharelados, 44 (quarenta e quatro) licenciaturas e 01 sequencial, totalizando 105 cursos de Bl cadastrados. Neste total, distintas áreas de concentração - em torno de 30 (trinta) - os organizam, com destaque para as Ciências e Tecnologia - e seus desdobramentos -, Educação do Campo, Artes, Saúde e Humanidades.

\section{Considerações Finais}

Ao longo deste artigo buscamos apresentar a linha do tempo da trajetória da educação superior brasileira, sobretudo das universidades desde suas principais heranças até os modelos mais recentes. Em seguida, observamos a conjuntura da educação superior no século XXI quanto à sua classificação, estrutura e princípios quando adentramos na proposta da Universidade Nova/UFBA Nova percebendo as singularidades de caráter inovador que a contorna. Em se tratando disso, cuidamos de compreender em especial, os 
Bacharelados Interdisciplinares enquanto proposta de reordenamento acadêmico, a partir de seus fundamentos, orientações práticas, competências profissionais, estrutura e desenho curricular.

No que concerne à trajetória das universidades brasileiras percebemos que, mesmo sendo muito jovem, é marcada por momentos bem distintos conforme o contexto político, social - tanto nacional como internacional - de cada época. Com seu surgimento datando meados de 1920, ou seja, ainda sequer completamos 100 anos de existência, justifica-se (talvez) os desafios percebidos da universidade atual em se adaptar ao novo, por carregar heranças emblemáticas de escolas humboldtianas, napoleônicas e americanas.

Novos tempos estabelecem novas conjunturas e o discurso para uma universidade para o século XXI se traduz na Universidade Nova com um «mescla tímida dos modelos existentes nos EUA e do Processo de Bolonha» (Catani, Lima \& Azevedo, 2008, p. 20) destacando repetidamente: indissociabilidade entre ensino pesquisa e extensão, autonomia, flexibilidade, expansão, democratização, função social, autoformação, aprendizagem em redes, mobilidade. Estas expressões traduzem uma fase do Brasil que se mostra politicamente exausto de opressão e, sobretudo, silenciamento que os anos anteriores lhe marcou. Almeja pela emancipação crítica de sujeitos e saberes em detrimento de qualquer forma de dominação a partir do reconhecimento de valores filosóficos como hiperconectividade, pensamento complexo, multi-intertransdisciplinaridade, paradigmas alternativos de formação, nos quais os Bacharelados Interdisciplinares ocupam parte nesse lugar com caráter inovador.

Acrescentando a toda essa discussão, parece-nos óbvio que os debates relativos à internacionalização da educação superior brasileira, a submissão aos países signatários do Processo de Bolonha ou aos modelos de escolas superiores norte-americanas situam-se em zonas periféricas quando se trata de uma problemática nuclear sobre a universidade como um lugar privilegiado para a defesa de um projeto nacional neste século XXI e que, portanto, deve ter e oferecer condições para que a comunidade nela inserida possa agir de acordo com seus interesses e na busca da consecução de projetos defendidos em lutas históricas. 


\section{Referências}

Almeida Filho, N. \& Santos. B. de S. (2008). A Universidade no século XXI: para uma universidade Nova. Coimbra: Almedina.

Anastasiou, L. G. C. \& Alves, L. P. (2004). Processos de ensinagem nas universidades: pressupostos para as estratégias de trabalho em aula. Joinville, SC: UNIVILLE.

Anastasiou, L. G. C. (1998). Metodologia do Ensino Superior: da prática docente a uma possível teoria pedagógica. Curitiba: IBPEX.

Brasil. Ministério da Educação. Secretaria de Educação Superior. (2009). Programa de Apoio a Planos de Reestruturação e Expansão das Universidades Federais Reuni 2008 - Relatório de Primeiro Ano. Brasília, DF: MEC: SESu.

Brasil. (2007). Diretrizes Gerais do Decreto n. 6.096 - Reuni - Reestruturação e Expansão das Universidades Federais. Brasilia, DF.

Brasil. (1998). Constituição da República Federativa do Brasil. Promulgada em 5 de outubro de 1988. Brasília: Senado Federal, 1988.

Brasil. Ministério da Educação. (2006). indissociabilidade entre ensino-pesquisaextensão e flexibilização curricular: uma visão da extensão/ Fórum de Pró-Reitores de Extensão das Universidades Públicas Brasileiras. Porto Alegre: UFRGS: Brasilia.

Catani, A. M.; Lima, L. C. \& Azevedo, M. L. N. (2008). O Processo de Bolonha, a avaliação da Educação Superior e algumas considerações sobre a Universidade Nova. Avaliação, Campinas; Sorocaba, SP, v.13, n.1, pp. 7-36, mar. Disponível em: $<$ http://www.scielo.br/pdf/aval/v13n1/a02v13n1>.

Chauí, Marilena. (2001). Escritos sobre a universidade. São Paulo: EDUNESP.

Fávero, M. L. A. A. (2014). Universidade no Brasil: das origens à Reforma Universitária de 1968. Revista Educar, n. 28. (pp. 17-36). Curitiba: Editora UFPR, 2006. Disponível em: http://www.scielo.br/pdf/er/n28/a03n28.pdf, acesso em Jul.

Fernandes, F.( 1975). Universidade brasileira: reforma ou revolução? São Paulo: Alfa-Ômega.

Morosini, M. (org.). (2006). A universidade no Brasil: concepções e modelos. Brasília: Instituto Nacional de Estudos e Pesquisas Educacionais Anísio Teixeira. Disponível em: ,http://www.publicacoes.inep.gov.br/arquivos/\%7B7E0103BC-2E4A4D94-AD06AA80565692FF\%7D_LIVRO\%20UNIVERSIDADES\%20COMPLETO.pdf>

Paula, M. de F. C. (2002). USP e UFRJ: A influência das concepções alemã e francesa em suas fundações. Tempo Social; Rev. Sociol. USP, S. Paulo, 14(2), 147161. Disponível em: <http://www.revistas.usp.br/ts/article/view/12387/14164>. Acesso em: 28 out. 2013. 
Reitores de universidades federais brasileiras pela reestruturação da educação superior no Brasil. (2006). Manifesto da universidade nova. Salvador-Bahia, Doc. On-line. Disponível em: <http://www.anped11.uerj.br/doc14/manifesto.rtf. Acesso em 22 de out 2015.

Tavares, M. da G. M. (1998). A Educação Superior Cidadã e a Extensão universitária: possibilidades e limitações na Lei 9.394/96 - LDB. In: Verçosa (Org.). E. de G.

Educação Superior \& Políticas Públicas: a implantação da nova LDB em debate. Alagoas: EDUFAL.

Teixeira, A. (1968). Uma perspectiva da educação superior no Brasil. Revista Brasileira de Estudos Pedagógicos. Brasília, v.50, n.111, jul/set pp. 21-28. 